\title{
AN ELECTRON MICROSCOPIC STUDY OF THE EFFECTS OF HYPERVITAMINOSIS A ON THE MATERNAL-EMBRYONIC RELATIONSHIP OF THE RAT AT 8 DAYS OF PREGNANCY
}

\author{
GILLIAN M. MORRISS \\ Department of Anatomy, University of Cambridge, Cambridge, England
}

(Received 15th May 1972)

\begin{abstract}
Summary. The decidual and trophoblastic tissue of the rat $5 \mathrm{hr}$ after the maternal administration of 100,000 i.u. vitamin A palmitate has been studied using light and electron microscopy.

The experimental tissue showed an increase in the surface area of membranes comparable to that previously described in cultures in the presence of excess vitamin A. Lipid droplets which may consist of vitamin A were seen in the blood, and most of the membrane damage was close to the capillaries. Vacuolated and distorted blood cells were observed, and cell débris was present in the blood space around the embryo. Decreased oxygen-carrying capacity and increased peripheral resistance were suggested as maternal vascular factors which may complement the direct embryotoxic effect of vitamin A in the teratogenic mechanism.
\end{abstract}

\section{INTRODUCTION}

The teratogenicity of hypervitaminosis A was discovered by Cohlan (1953). Giroud, Gounelle \& Martinet (1957) reported that the levels of vitamin A in 14-day embryos from female rats given 60,000 i.u. on Days 11,12 and 13 were higher than the levels in 14-day control embryos, thus suggesting a direct teratogenic effect. Woollam \& Millen (1960) combined the administration of vitamin $\mathrm{A}$ with other substances. They reported that the teratogenic activity was accentuated by cortisone and methylthiouracil, and that a protective effect was exerted by the B-group vitamins, insulin and, most markedly, by thyroxine. From these results, they postulated that the teratogenic mechanism was an interference with the carbohydrate metabolism of the mother, placenta or fetus. Their results were challenged by Cohlan \& Stone (1961) but supported by Takekoshi (1964), who suggested that the fall in blood thyroxine levels caused by excess vitamin A was an important factor in the teratogenic mechanism and the reason for the potentiating effect of methylthiouracil.

Examination of the early effects on the embryo itself was made in the golden hamster by Marin-Padilla \& Ferm (1965) and Marin-Padilla (1966). Using light microscopy, they noted early alterations in the mesoderm, and interpreted these as the cause of the abnormal development of the central nervous system. 
Morriss (1972), using electron microscopy, studied the early changes in the cells of 8-day rat embryos following excess maternal vitamin A. She confirmed and extended the results of Marin-Padilla (1966). The ultrastructural changes were comparable to those described in various in-vitro situations of hypervitaminosis A (e.g. Jackson \& Fell, 1963). It seems likely, therefore, that the teratogen has a direct effect on the embryo. The present paper describes the ultrastructural appearance of the decidual, trophoblastic and blood cells $5 \mathrm{hr}$ after maternal vitamin A administration. These have been studied in order to determine whether any effects observable in this way might be implicated as maternal components of the teratogenic mechanism.

\section{EXPLANATION OF PLATES}

All micrographs show sections of 8-day pregnant rat tissues. Key to symbols: B, blood space; C, capillary; Co, collagen; D, decidual tissue; DCS, distorted cell surfaces; $\mathrm{E}$, embryo; En, endoderm; ER, endoplasmic reticulum; L, lipid droplet; R, Reichert's membrane; SM, swollen mitochondria; T, trophoblast.

\section{PLATE 1}

Light micrographs

Fig. 1. Transverse section of the uterus of a control 8-day pregnant rat. Paraffin-waxembedded section, stained H. \& E. $\times 17$.

Fig. 2. Control embryo, trophoblast and maternal tissues. Embryo (left) cut tangentially. In Araldite section, stained with toluidine blue. $\times 215$.

Fig. 3. Transverse section of a control embryo (top), and the surrounding tissues. Araldite section, toluidine blue. $\times 860$.

Fig. 4. Decidual tissue $5 \mathrm{hr}$ after vitamin A administration. Lipid droplets in a capillary are arrowed. Araldite section, toluidine blue. $\times 860$.

\section{PLATE 2}

Electron micrographs

FrG. 5. Controls: decidual tissue. The granular endoplasmic reticulum forms a mass of vacuoles varying in size from cell to cell. $\times 2260$.

Fig. 6. Part of a decidual cell to illustrate the form of the endoplasmic reticulum. $\times 11,240$.

FIG. 7. Decidual tissue, trophoblast, blood space and embryo. $\times 2230$.

\section{PLATE 3}

FIG. 8. Section taken $5 \mathrm{hr}$ after vitamin A administration: decidual tissue with capillary. Swollen mitochondria in endothelial cell and adjacent area of decidual cell; distorted cell surface; leucocyte with vacuoles (arrowed). $\times 8380$.

Fig. 9. Part of a decidual cell containing swollen mitochondria, and having a greatly distorted cell surface. $\times 6700$.

Fig. 10. Trophoblast with capillary containing several erythrocytes with vacuoles (arrowed). $\times 8400$.

\section{PLATE 4}

Fig. 11. Trophoblast, blood space and embryo. Degenerating cells and cell components lie in the blood space in a disorganized manner, along with the maternal erythrocytes. $\times 1120$.

FIG. 12. Swollen endoplasmic reticulum, mitochondria, ribosomes, lipid droplets and vacuolated and distorted erythrocytes in the blood space. Abnormal microvilli and cytoplasmic budding in the extraembryonic endoderm of the embryo. $\times 13,400$.

\section{PLATE 5}

FIG. 13. Ectoplacental cone. Control section. Erythrocytes in various stages of phagocytosis and lysis by the trophoblast cells. $\times 3760$.

Fig. 14. Section taken $5 \mathrm{hr}$ after maternal vitamin A administration. Vacuolated erythrocytes; trophoblast cells with abnormal cytoplasm and pycnotic nuclei, showing no evidence of phagocytosis; large amount of collagen-like material. $\times 5550$. Inset: collagen-like material. $\times 16,500$. 
PLATE 1
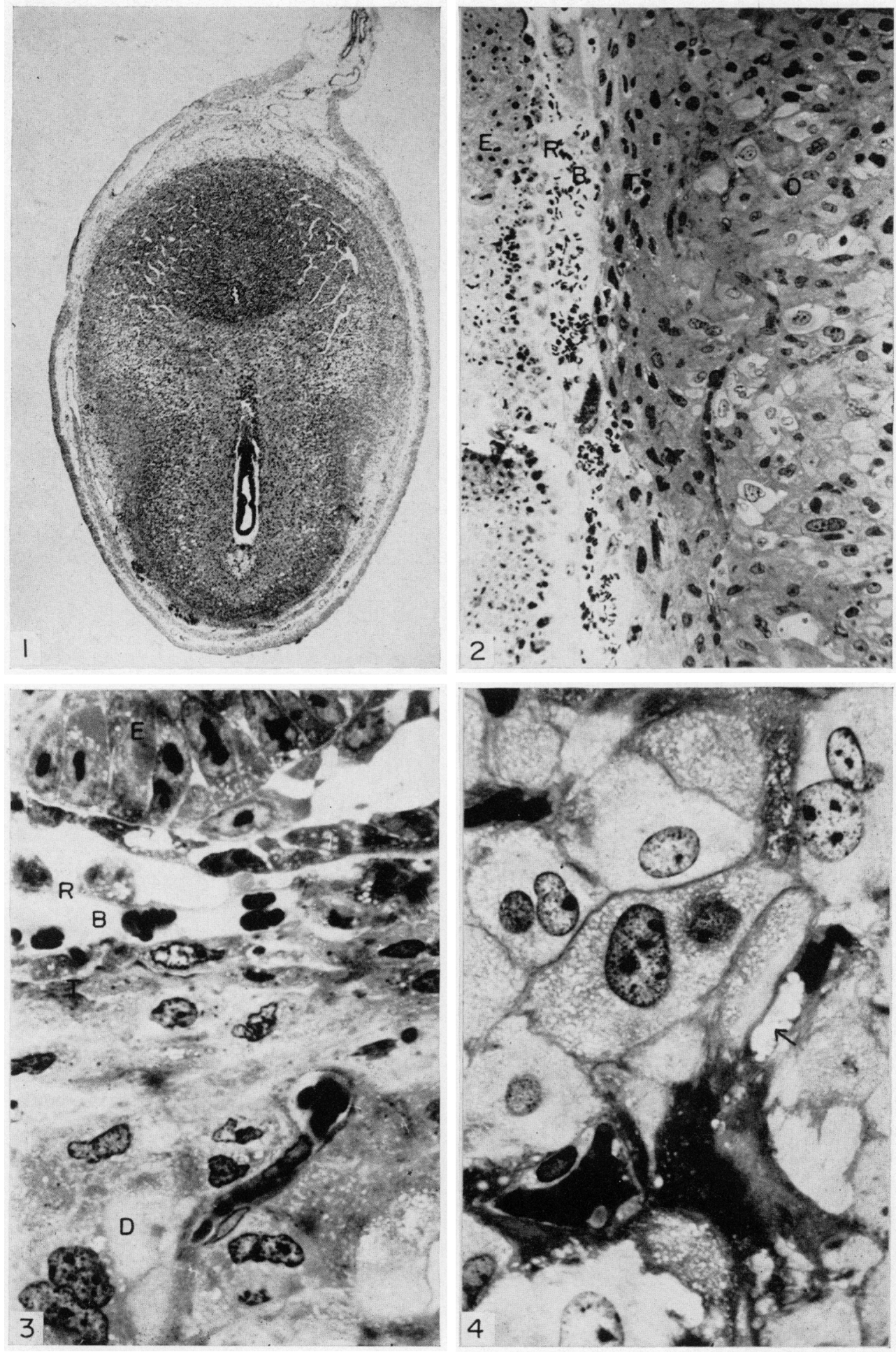

(Facing p. 452) 
PLATE 2

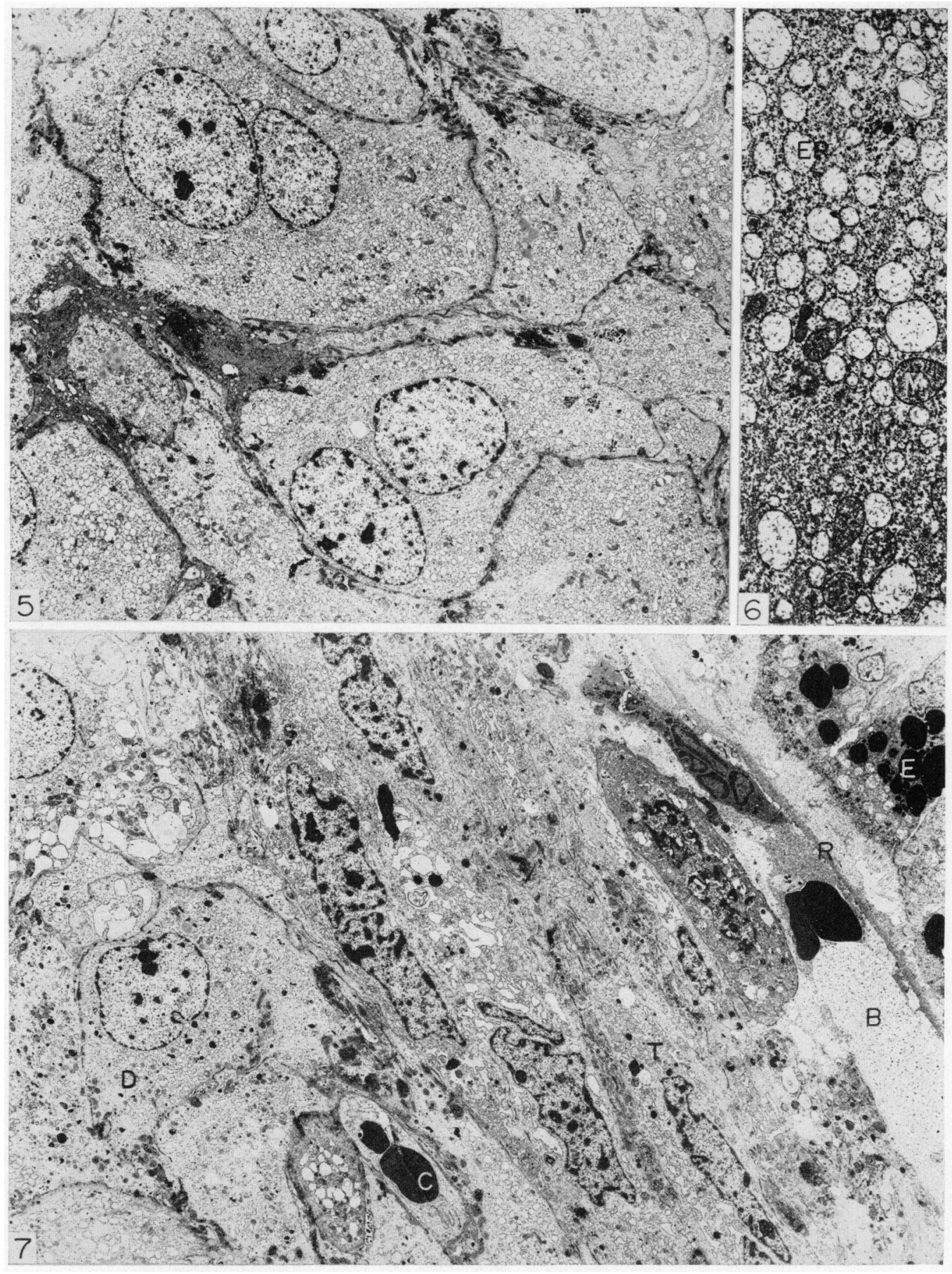




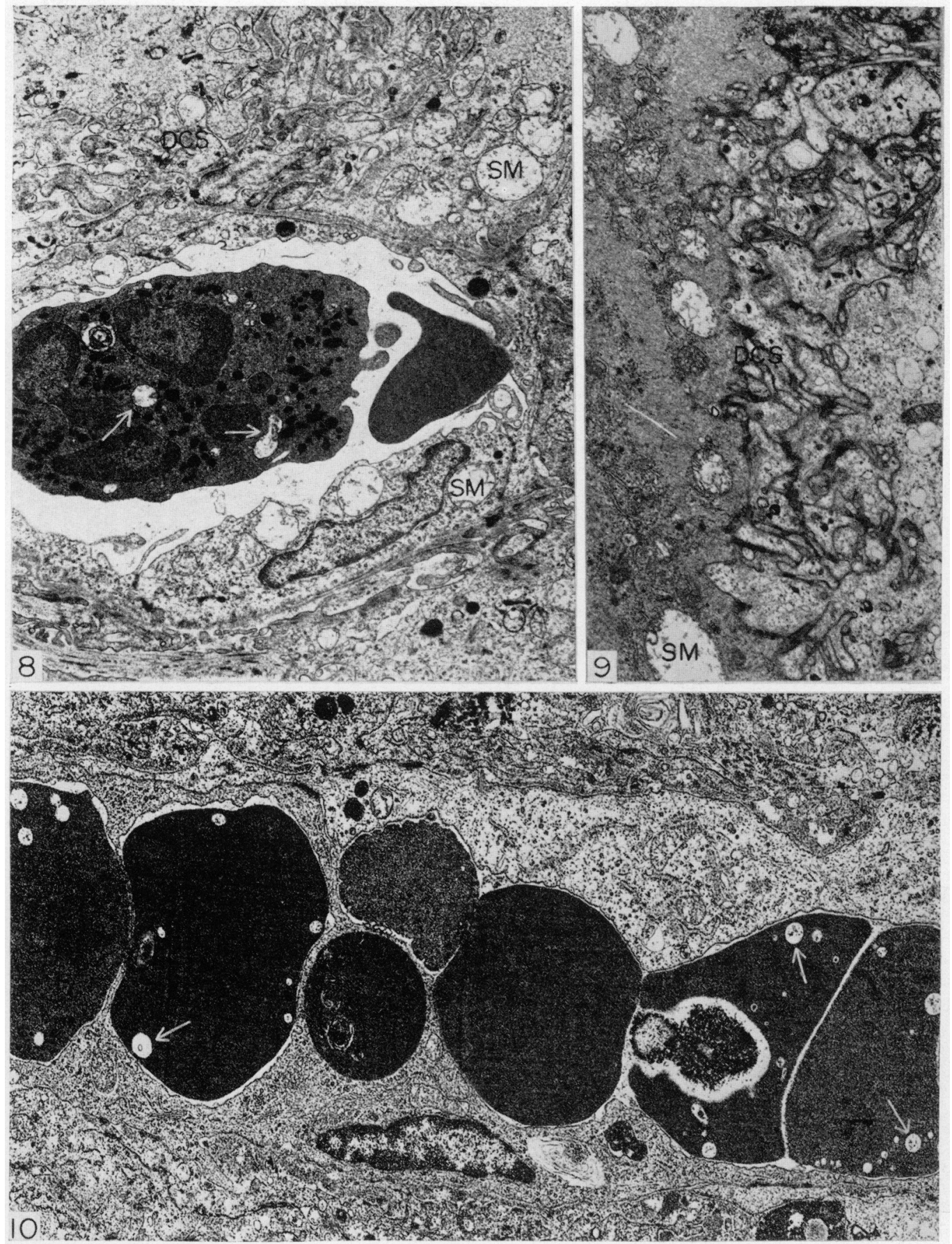


PLATE 4




PLATE 5

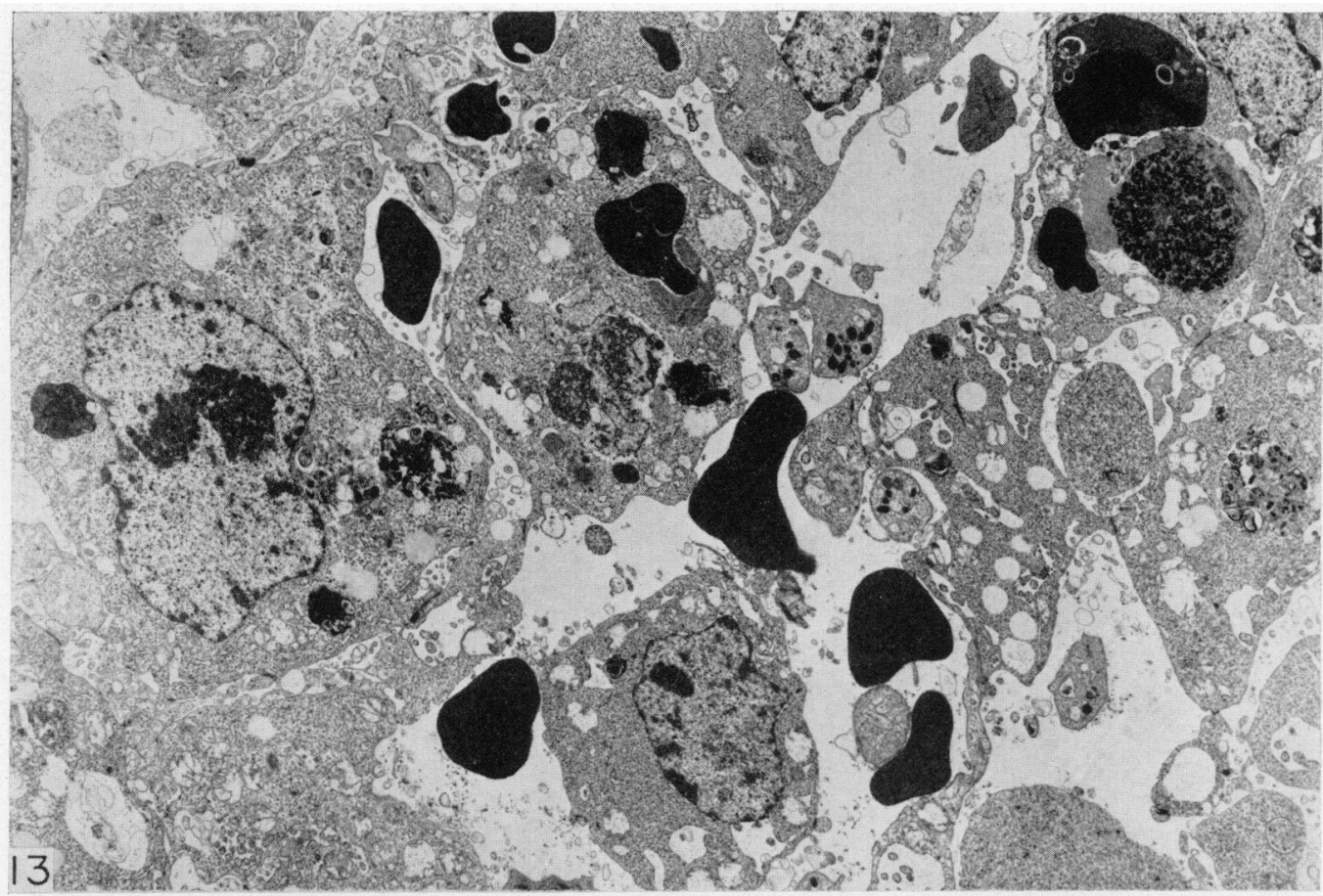

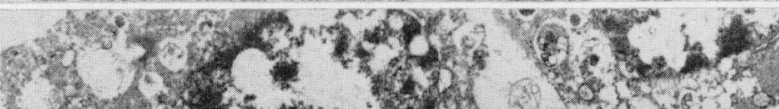

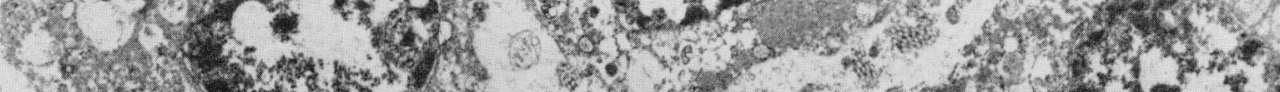

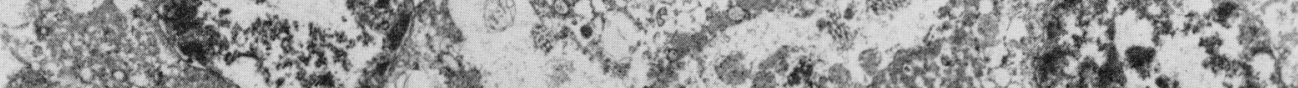

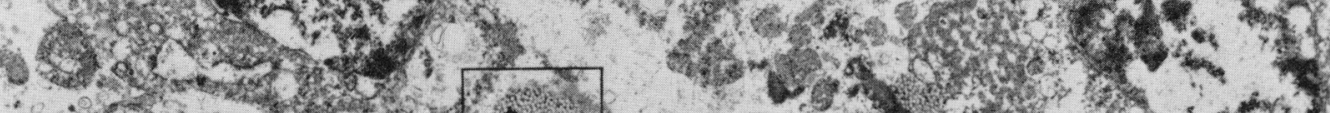

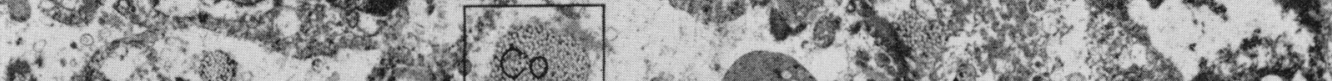

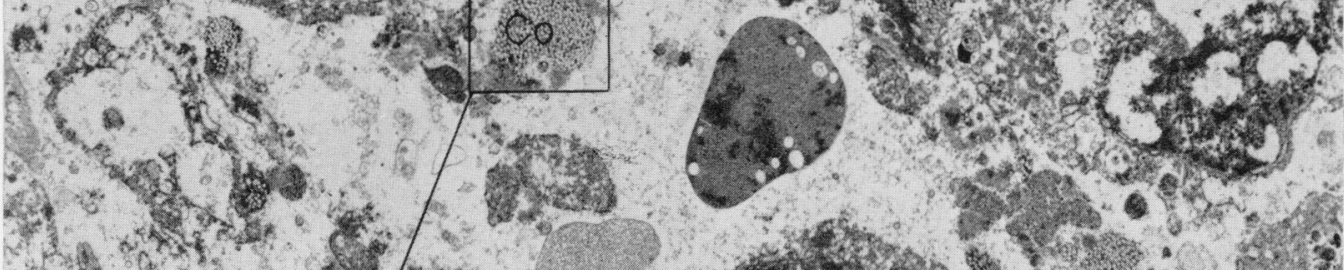



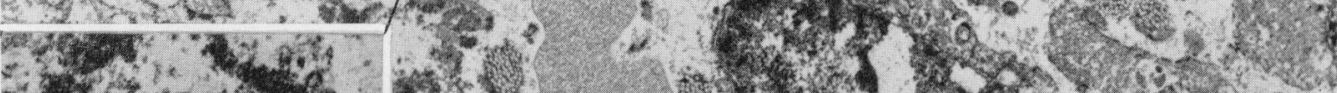

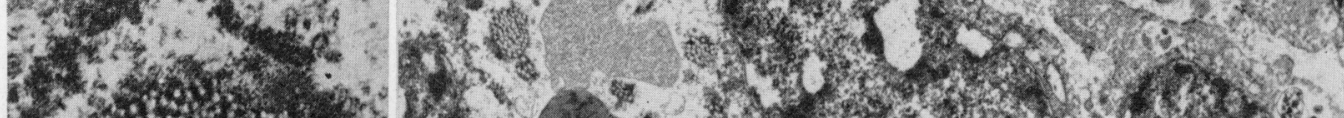
B. Hot. Y.7.3.

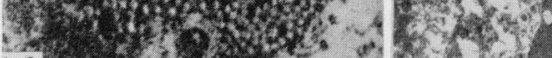

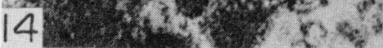

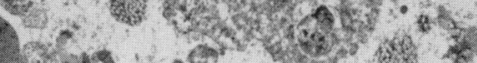




\section{MATERIALS AND METHODS}

Decidual tissue from 8-day pregnant rats was prepared as follows: after being removed from the uterus and placed in Tyrode saline, the pear-shaped decidua was trimmed to within $0.5 \mathrm{~mm}$ of the embryo on all sides. The trimmed tissue pieces containing embryos were fixed in $4 \%$ phosphate-buffered glutaraldehyde. They were then cut with a razor blade into pieces approximately $1 \mathrm{~mm}^{3}$ in size. These were post-fixed in phosphate-buffered osmium tetroxide, dehydrated and embedded in Araldite. The final embedding was made directly in polythene capsules shaped ready for cutting, so that the orientation of the sections was a matter of chance. Suitable areas (cutting through embryo or ectoplacental cone in addition to decidual tissue) were found by the examination of thick sections with the light microscope. From these areas, thin sections were cut, double-stained in uranyl acetate and lead citrate, and viewed with a Philips EM 300 electron microscope.

Three control and four vitamin A-treated Wistar-derived rats were used. The day on which spermatozoa were found in the vaginal smear was designated Day 0 of pregnancy. The vitamin A preparation used was an aqueous suspension of vitamin A palmitate (Roche Products Ltd); it was administered subcutaneously between 09.00 and 09.30 hours on Day 8 of pregnancy.

\section{OBSERVATIONS}

The rat embryo on Day 8 of pregnancy is embedded in a mass of spongy decidual tissue which almost completely occludes the lumen of the uterus (Pl. 1, Fig. 1). Maternal blood from the uterine artery traverses the decidua by means of many small capillaries which open into the blood space surrounding the embryo (PI. 1, Figs 2 and 3). Similar capillaries return the blood to the uterine vein. The embryo is thus surrounded by flowing maternal blood, from which it is separated only by Reichert's membrane. At the light microscope level, decidual tissue from rats killed $5 \mathrm{hr}$ after vitamin A administration was indistinguishable from control tissue, except for groups of lipid droplets which were frequently observed within capillaries (PI. 1, Fig. 4).

Electron microscopy of decidual tissue from control rats showed that the cells were irregular in shape and densely packed (Pl. 2, Fig. 5). The nuclei were rounded in section, and were frequently either U-shaped or two to the cell. The rough endoplasmic reticulum cisternae formed, to a greater or lesser degree in the different cells, a mass of vacuoles (Pl. 2, Fig. 6). The trophoblastic cells situated between the decidual cells and the embryo or blood space were flattened in shape, and contained irregular nuclei (Pl. 2, Fig. 7). By $5 \mathrm{hr}$ after vitamin A administration, the cell surfaces were frequently observed to be greatly increased in area, being thrown into a mass of folds and protuberances. This was especially common close to the capillaries (P1. 3, Figs 8 and 9), and swollen mitochondria were also common in these regions. The erythrocytes and leucocytes were frequently distorted or vacuolated (PI. 3, Figs 8 and 10). In the blood space around the embryo, degenerating cells and cell components were present (Pl. 4, Fig. 11). Lipid droplets of moderate electron density were com- 
mon, often in groups. Plate 4, Fig. 12 illustrates the close relationship between lipid droplets and vacuolated erythrocytes on one side of Reichert's membrane with an irregular appearance of the endodermal microvilli on the other.

Trophoblast cells from the ectoplacental cones of control rats formed a loose network in the meshes of which were many maternal erythrocytes and thrombocytes (Pl. 5, Fig. 13). These maternal cells were apparently engulfed by the trophoblast cells, undergoing subsequent degeneration by the formation of heterophagic vacuoles. In ectoplacental cone tissue from rats killed $5 \mathrm{hr}$ after vitamin A administration, the cells appeared to be very irregular, both in shape and internal organization, compared with the controls (Pl. 5, Fig. 14). Clumping of material appeared to have taken place both in the cytoplasm and the nuclei. There was a large amount of collagen-like material between the cells. Fewer erythrocytes were seen within the cells, and those outside them were frequently vacuolated.

\section{DISCUSSION}

Within 30 min of a subcutaneous injection of vitamin A palmitate in the rat, electron microscopy of the maternal liver showed that large numbers of lipid droplets began to arrive in the sinusoids, from where they were engulfed by the Kupffer and hepatic cells; at the same time, an increase in the vitamin A content of these cells was demonstrable by fluorescence microscopy (G. M. Morriss, unpublished preliminary work for the present study). Geelen (1972) has shown a strong vitamin A fluorescence in the decidual cells of 9-day rat embryos following maternal injections of 50,000 i.u. vitamin A palmitate on 3 consecutive days. The fluorescence was concentrated around the capillaries and outside Reichert's membrane. The lipid droplets observed electron microscopically in the decidual capillaries and blood space in the present study are identical to those seen in the liver; the coincidence of the fluorescence in both situations provides additional evidence that they may consist of vitamin A. Further, vitamin A is a semi-saturated lipid and would be expected to have a moderate electron density, as is the case here. Such lipid droplets were also observed in the embryonic cells (P1. 4, Fig. 11). Ganguly (1969) stated that vitamin A palmitate in the small intestine is hydrolysed to retinol before absorption by the mucosal cells, and re-esterified before passing into the lymph. A similar process may be involved in its transfer across Reichert's membrane. The ultrastructural effects of excess vitamin A have previously been described in a number of situations in vitro: rat dermal fibroblasts (Dingle \& Lucy, 1965; Daniel, Dingle, Glauert \& Lucy, 1966); embryonic chicken skin (Jackson \& Fell, 1963); erythrocytes (Glauert, Daniel, Lucy \& Dingle, 1963). The effects were mainly on membranes, causing irregularities of the plasma membrane of the fibroblasts, swelling of mitochondria, vacuolation of the erythrocyte membranes, and an uptake of fluid by both chick epidermal cells and erythrocytes which suggested a change in membrane permeability. Vitamin A has also been shown to bring about an increase in the surface area of an 'artificial membrane', i.e. a lecithin/cholesterol monolayer (Bangham, Dingle \& Lucy, 1964). Dingle \& Lucy (1962) proposed that membranes might be a physiological site of the vitamin. 
In the present study, the apparent increase in surface area of the membranes of decidual cells following excess maternal vitamin A administration corresponds to the observations in vitro referred to above. The number of cells containing swollen mitochondria was, however, small, and it seems unlikely that this phenomenon would have any effect on the embryos. The effect on blood cells, both red and white, was more general, and resembled closely the early stages of erythrocyte lysis in the presence of $10 \mu \mathrm{g} / \mathrm{ml}$ retinol described by Glauert et al. (1963). In that situation, loss of haemoglobin did not occur until breaks appeared in the membranes, and this was not observed in the present study. However, the penetration of the membrane by vitamin A followed by vacuole formation is likely to have some effect on the oxygen uptake and release mechanism. Such an effect, depending on its severity and duration, might cause a temporary state of hypoxia. Ingalls, Curley \& Prindle (1950) placed pregnant mice in a low pressure chamber at $260 \mathrm{~mm} \mathrm{Hg}$ (equivalent to about $27,000 \mathrm{ft}$ above sea level) for $5 \mathrm{hr}$ from the 6 th to 14 th day of pregnancy, and found that a significant number of young had malformations including cleft palate and exencephaly. It is possible that maternal hypoxia might supplement the direct teratogenic action of hypervitaminosis A. In addition, the rate of flow of maternal blood around the embryo is likely to be reduced by an increased peripheral resistance resulting from the presence of cell débris in the blood space.

\section{AGKNOWLEDGMENTS}

This work was supported by the Wellcome Trust. I am grateful to Dr D. H. M. Woollam for advice, to Professor R. J. Harrison for the provision of laboratory facilities, to Mr J. F. Crane for assistance with photography, and to $\operatorname{Dr} \mathrm{N}$. T. Pollitt of Roche Products Ltd for supplying the vitamin A.

\section{REFERENCES}

Bangham, A. D., Dingle, J. T. \& Lucy, J. A. (1964) Studies on the mode of action of excess of vitamin A. 9. Penetration of lipid monolayers by compounds in the vitamin A series. Biochem. F. 90, 133.

Cohlan, S. Q. (1953) Excessive intake of vitamin A as a cause of congenital anomalies in the rat. Science, N.Y. 117, 535.

Cohlan, S. Q.\& Stone, S. M. (1961) Observations on the effects of experimental endocrine procedures on the teratogenic action of hypervitaminosis-A in the rat. Biologia Neonat. 3, 330.

Daniel, M. R., Dingle, J. T., Glauert, A. M. \& Lucy, J. A. (1966) The action of excess of vitamin A alcohol on the fine structure of rat dermal fibroblasts. F. Cell Biol. 30, 465.

Dinale, J. T. \& LucY, J. A. (1962) Studies on the mode of action of excess of vitamin A. 5. The effect of vitamin A on the stability of the erythrocyte membrane. Biochem. F. 84, 611 .

Dingle, J. T. \& Lucy, J. A. (1965) Vitamin A carotenoids, and cell function. Biol. Rev. 40, 422.

Ganguly, J. (1969) Absorption of vitamin A. Am. F. clin. Nutr. 22, 923.

GeELEN, J. A. G. (1972) The localization of vitamin A in the pregnant rat by means of fluorescence microscopy. Teratology, 6, 19.

Giroud, A., Gounelle, H. \& Martinet, M. (1957) Donnés quantitatives sur le taux de la vitamin A chez le rat lors d'expériences de tératogénèse par hypervitaminose A. Bull. Soc. Chim. biol. 39, 331 .

Glauert, A. M., Daniel, M. R., Lucy, J. A. \& Dingle, J. T. (1963) Studies on the mode of action of excess of vitamin A. 7. Changes in the fine structure of erythrocytes during haemolysis. F. Cell Biol. 17, 111.

Ingalls, T. H., Gurley, F.J. \& Prindle, R. A. (1950) Anoxia as a cause of fetal death and congenital defect in the mouse. Am. F. Dis. Child. 80, 34.

JACKSON, S. F. \& FELL, H. B. (1963) Epidermal fine structure in embryonic chicken skin during atypical differentiation induced by vitamin A in culture. Devl Biol. 7, 394. 
Marin-Padilla, M. (1966) Mesodermal alterations induced by hypervitaminosis A. F. Embryol. exp. Morph. 15, 261.

MARin-PAdilla, M. \& FerM, V. H. (1965) Somite necrosis and developmental malformations induced by vitamin $A$ in the golden hamster. F. Embryol. exp. Morph. 13, 1.

Morriss, G. M. (1972) The teratogenesis of hypervitaminosis A. Ph.D. thesis, University of Cambridge.

TAKeKoshi, S. (1964) The mechanism of vitamin A induced teratogenesis. F. Embryol. exp. Morph. 12, 263.

Woollam, D. H. M. \& Millen, J. W. (1960) The modification of the activity of certain agents exerting a deleterious effect on the development of the mammalian embryo. In: Gongenital Malformations, p. 158. Eds. G. E. W. Wolstenholme and M. O'Connor. Churchill, London. 